\title{
Expected efficiency of selection for growth in a French beef cattle breeding scheme. II. Prediction of asymptotic genetic gain in a heterogeneous population
}

\author{
F Phocas, JJ Colleau, F Ménissier \\ Institut national de la recherche agronomique, station de génétique \\ quantitative et appliquée, 78352 Jouy-en-Josas cedex, France
}

(Received 24 February 1994; accepted 18 October 1994)

\begin{abstract}
Summary - Asymptotic genetic gains and lags are derived in French beef cattle breeding schemes for an objective including direct and maternal effects on growth. A simple general method using matrix algebra is presented to simultaneously calculate asymptotic genetic gains and lags, whatever the population structure. The heterogeneity of use of artificial insemination (AI) in selection herds is considered. At the same overall rate of AI use, larger asymptotic genetic gains can be obtained by concentrating AI in only a fraction of the herds instead of keeping the same lower rate in all herds. An application concerns the Limousin selection nucleus, where $23 \%$ of calves are bred by $\mathrm{AI}$ in only $50 \%$ of the herds. When an aggregate breeding objective for growth is considered, positive annual asymptotic genetic gains are expected in both direct $(+0.13$ genetic standard deviation) and maternal effects $(+0.05$ genetic standard deviation) on growth, despite the negative estimates (around -0.2 ) of genetic direct-maternal correlations. The major part of the genetic gains in direct and maternal effects are due to AI sire selection and dam selection respectively. Taking into account sampling uncertainty in estimates of preweaning genetic parameters leads to the conclusion that the predicted asymptotic response in maternal effects is positive with a very high probability. Nevertheless, strongly negative (around -0.6) estimates of correlations between direct and maternal effects lead to negative responses in maternal effects.
\end{abstract}

beef cattle / growth / asymptotic genetic gain / open nucleus / sampling variance

Résumé - Prédiction de l'efficacité d'un schéma de sélection français sur la croissance en race bovine allaitante. II. Prédiction du progrès génétique asymptotique dans une population hétérogène. Dans un schéma de sélection français en race bovine allaitante, les progrès et les retards génétiques asymptotiques sont calculés pour un objectif de sélection incluant effects directs et maternels sur la croissance. Quelle que soit la structure de la population considérée, une formulation matricielle simple permet de calculer simultanément ces progrès et ces retards génétiques asymptotiques. Ainsi, 
l'utilisation différentielle de l'insémination artificielle (IA) dans les troupeaux de sélection est aisément prise en compte. Pour un même taux d'IA sur l'ensemble du noyau de sélection, des progrès génétiques plus importants peuvent être obtenus en utilisant l'IA dans une partie seulement des troupeaux, plutôt qu'en considérant une plus faible utilisation de l'IA, mais identique d'un troupeau à un autre. Les paramètres démographiques et génétiques utilisés correspondent au noyau de sélection de la race Limousine, où $23 \%$ des veaux sont procréés par IA dans seulement $50 \%$ des troupeaux. Pour un objectif de sélection composite concernant les caractères de croissance, des progrès génétiques annuels positifs sont espérés tant pour les effets directs (+0,13 écart type génétique) que pour les effets maternels $(+0,05$ écart type génétique), malgré les estimées négatives (autour de $-0,2)$ des corrélations génétiques entre ces effets. Ces progrès génétiques sont essentiellement dus à la sélection des taureaux d'IA pour les effets directs et à la sélection des mères pour les effets maternels. La prise en compte d'une incertitude d'échantillonnage sur les estimées des paramètres génétiques pré-sevrage aboutit à la conclusion que la réponse prédite sur les effets maternels est positive avec une très forte probabilité. Néanmoins, des estimées très fortement négatives (autour de $-0,6$ ) des corrélations entre effets directs et maternels induisent des réponses négatives sur les effets maternels.

bovin allaitant / croissance / progrès génétique asymptotique / noyau ouvert / variance d'échantillonnage

\section{INTRODUCTION}

Animal breeding schemes are usually illustrated by a pyramid with several tiers. For instance, beef cattle breeding programs account for 2 main tiers in the pyramid: a selection nucleus at the apex and a base commercial population, with a downward gene flow. In French beef cattle breeding schemes, the nucleus is not homogeneous because of the use of 2 reproduction methods, artificial insemination (AI) and natural service (NS). A significant proportion of herds do not even use AI. Thus, the nucleus can be split into several tiers depending on the magnitude of AI use. These tiers must be considered as open subnuclei since there are gene exchanges between them. Moreover, the nucleus is said to be heterogeneous, since newborn calves, candidates for selection, can be classified into different groups for each sex, according to their genetic level; indeed, a higher average genetic level is expected for calves bred by AI than for calves bred by NS.

The aim of this paper is to predict asymptotic genetic gains in growth for a French beef cattle breeding scheme, when significant heterogeneity of AI use is observed between herds. The effect on this prediction of sampling uncertainty in estimates of preweaning genetic parameters is examined. A simple matrix method is presented to calculate simultaneously asymptotic genetic gains and lags for any population structure. An application concerns the Limousin breeding scheme where the selection nucleus can be divided into 2 equal tiers: herds with a constant rate of AI use and herds without AI use. The prediction of the genetic gain is for a global breeding objective $\mathrm{Hg}$ for growth traits, derived in a previous paper (Phocas et al, 1995). 


\section{MATERIALS AND METHODS}

The abbreviations used in figures, tables and text are listed in Appendix I.

\section{Modelling of the breeding scheme}

\section{Herd structure and matings}

With 600000 cows, the Limousin breed is the second French beef cattle breed. About $10 \%$ of these cows are registered and recorded, constituting the selection nucleus of the breed. In the nucleus, $11.5 \%$ of the cows are inseminated, but only $50 \%$ of the herds use AI. Thus, the nucleus must be split into 2 tiers: a tier composed of the $50 \%$ of herds with a rate of $\mathrm{AI}$ equal to $23 \%$ and another tier composed of the $50 \%$ of herds without AI use. A hypothetical one-tier nucleus where AI is uniformly used in all herds (11.5\%) was also modelled in order to evaluate the change in efficiency related to the heterogeneity of nucleus herds.

Matings were assumed to be independent of the origin of the parents and of the way they were selected. Selection and reproduction of females were completed in their native tier.

\section{Bull selection}

Three types of bulls were selected among the 19000 males recorded at weaning.

\section{AI bulls}

AI bull selection was described in a previous paper (Phocas et al, 1995). The simplified scheme proposed in that paper was considered here. AI bulls were selected for a first use at 5 years of age, after a 3-stage selection with independent culling levels. The best 600 males for weaning weight (W210) were evaluated in performance test station on weight at $400 \mathrm{~d}$ (W400). The best 50 males for this second trait were then evaluated by progeny test on farm according to an optimum index $\left(I_{b}\right)$ combining 2 information sources, the average W210 of 30 sons and the average W120 of 20 daughters' calves. This last information was the only criterion on maternal performance considered for bull selection. Finally 20 males were selected as AI bulls for both nucleus and commercial herds.

After their qualification for AI, bulls used in the nucleus were selected on their progeny index independently of their age and origin, with a selection pressure of $7 \%$. The number of available semen doses for a bull was assumed to be constant over the 9 years of its potential utilization.

\section{Station NS bulls}

Two hundred males were selected on test station performance: 30 of them were the males evaluated by progeny test, but not selected for AI use; the other 170 were the best males on W400 following the 50 males selected for a progeny test. 
After their qualification as station NS bulls, bulls used in the nucleus were selected independently of their age and origin, with a selection rate of $80 \%$. Their first use occurred at 2 years of age and their last use at 10 years.

\section{Farm NS bulls}

A total of 1300 other bulls were selected for NS use: 380 were those evaluated at a performance test station, but not selected as AI or station NS bulls; the other 920 bulls were the males ranked on W210 immediately after the best 600 were selected for a station evaluation. Their first use occurred at 1 year old and their last use at a maximum of 9 years old. After their qualification as farm NS bulls, bulls were chosen at random each year of their use.

\section{Cow selection}

A total of $50 \%$ of females born were selected for replacement within tier and for a first calving at 2.5 years old. Selection is performed on an optimum index $\left(I_{0}\right)$ combining the individual W120 and the average W120 of 10 paternal half-sisters' calves ( 1 calf recorded per half-sister).

After this first selection step, cow dams were chosen at random until a last calving at 14 years old.

Bull dams were chosen among females with at least one recorded calf and with a selection rate of $63 \%$. Selection was performed on an optimum index $\left(I_{\mathrm{d}}\right)$ combining the average W120 of cows' own calves and the 2 criteria used for heifer selection. This index depends on the age of the cow (3-13 years), since it was assumed that each year an additional calf is recorded.

\section{Description of cohorts of animals}

\section{Cohorts at birth}

Let $n$ be the number of cohorts $(Y)$ of newborn animals. In our applications, $n$ equals 4 or 6 . In the one-tier nucleus, $Y=1$ to 4 are cohorts of, respectively, males bred by AI (M1), males bred by NS (M2), females bred by AI (F1) and females bred by NS (F2). In the two-tier nucleus, $Y=1$ to 6 are cohorts of, respectively, males bred by AI (M1), males bred by NS in the tier with AI use (M2), males bred by NS in the tier without AI use (M3), females bred by AI (F1), females bred by NS in the tier with AI use (F2) and females bred by NS in the other tier (F3).

\section{Cohorts of candidates for selection}

The animals were grouped into cohorts defined by sex, age, origin (native tier and reproduction method), mode of mating (AI or NS) and mode of selection (farm or station). Table I presents the connection between origins of parental cohorts and cohorts at birth. 
Table I. Connection between origins of parental and offspring cohorts.

\begin{tabular}{|c|c|c|}
\hline Cohorts at birth & $\begin{array}{l}\text { Corresponding } \\
\text { cohorts of sires }\end{array}$ & $\begin{array}{l}\text { Corresponding } \\
\text { cohorts of dams }\end{array}$ \\
\hline \multicolumn{3}{|l|}{ Bred by $A I$} \\
\hline $\begin{array}{l}\text { Males: M1 } \\
\text { Females: F1 }\end{array}$ & M1, M2, M3: 6-14 years & $\begin{array}{l}\text { F1, F2: } 4-14 \text { years } \\
\text { F1, F2: 2-14 years }\end{array}$ \\
\hline \multicolumn{3}{|l|}{$\begin{array}{l}\text { Bred by NS } \\
\text { in herds using } A I\end{array}$} \\
\hline $\begin{array}{l}\text { Males: M2 } \\
\text { Females: F2 }\end{array}$ & $\begin{array}{l}\text { M1, M2, M3: station NS bulls: } 3-11 \text { years } \\
\text { and farm NS bulls: } 2-10 \text { years }\end{array}$ & $\begin{array}{l}\mathrm{F} 1, \mathrm{~F} 2: 4-14 \text { years } \\
\mathrm{F} 1, \mathrm{~F} 2: 2-14 \text { years }\end{array}$ \\
\hline \multicolumn{3}{|l|}{$\begin{array}{l}\text { Bred by NS } \\
\text { in herds using } A I\end{array}$} \\
\hline $\begin{array}{l}\text { Males: M3 } \\
\text { Females: F3 }\end{array}$ & $\begin{array}{l}\text { M1, M2, M3: station NS bulls: } 3-11 \text { years } \\
\text { and farm NS bulls: } 2-10 \text { years }\end{array}$ & $\begin{array}{l}\text { F3: } 4-14 \text { years } \\
\text { F3: } 2-14 \text { years }\end{array}$ \\
\hline
\end{tabular}

\section{Derivation of annual genetic gain and genetic lags}

The asymptotic genetic gain in open populations is usually derived by calculating the year-by-year change of genetic values until the steady state is reached. Convergence can be accelerated by using deterministic prediction such as the Rendel and Robertson (1950) formula. However this formula is only valid for closed and homogeneous populations. In beef cattle breeding schemes, sires (or dams) are selected within an age class among several groups of different average genetic merits at birth, such as a group of animals bred by AI and a group of animals bred by NS. Therefore, the unimodal assumption of candidates for selection within an age class is not valid. Moreover, the probabilities of origin of each kind of breeding animals (for instance, AI and NS bulls) are not the same. In such heterogeneous populations, a 'gene flow' analysis is needed to find the weightings of the different selection differentials in order to calculate the asymptotic genetic gain. These weightings are generally derived for special situations. James (1977) gave an analytical expression for the steady-state genetic gain in an open nucleus, $i e$ a 2-tier population structure, with discrete generations. Shepherd and Kinghorn (1992) derived an analytical expression in a 3-tier population structure. Elsen (1993) gave general matrix formulae to compute successively asymptotic genetic gain and genetic lags for any population structure. Here, we propose a simpler and more direct matrix formulation which provides these parameters simultaneously for any population structure and without any calculation of eigenvectors.

The previous methods use known selection differentials, generation intervals and proportions of the different kinds of parents per cohort of offspring. However these parameters depend on genetic lags between all cohorts of candidates to selection. Therefore, a recursive 2-step algorithm is used to calculate asymptotic genetic evolution: (i) derivation of selection differentials, generation intervals and 
proportions of parents used by the Ducrocq and Quaas (1988) method; (ii) knowing the parameters in (i), derivation of asymptotic genetic gains and lags by our matrix method; and (iii) iterative calculations of (i) and (ii) until convergence is reached (about 6 iterations instead of 40 for a year-by-year algorithm). The first step of this algorithm makes use of the asymptotic results derived in the second step. Thus, between 2 cohorts of animals of the same origin but of different ages $(i$ and $j$ ) the genetic lag at birth is: $(j-i) \Delta G$. The genetic lags at birth between cohorts of candidates for selection with different origins are also used recursively to derive selection differentials.

Ducrocq and Quaas (1988) have previously used such a 2-step algorithm to derive genetic gain by the Rendel and Robertson (1950) formula in a closed homogeneous population with overlapping generations.

First step of the algorithm: derivation of selection differentials, generation intervals and proportions of each kind of parent used to produce a given offspring

Selection differentials are calculated for all the variables considered in the selection objective and criteria (A120, M120, A210, M210, A400 and A500), in order to rebuild a means of selection indices for all cohorts of candidates for selection for the next iteration. In order to simplify notations, the subscripts indicating the variable considered are dropped in the following equations.

Animals, from age $(i)$ and origin $(X)$ classes, are selected in $W$ (farm or station) to produce offspring $Y$, by using the same truncation point across classes. This maximizes the average selection differential $S_{X Y W}$ and simultaneously optimizes the generation interval and the proportions of the different kinds $(X)$ of parents used to produce a given kind $(Y)$ of offspring. Animals are assumed to be unrelated and within a class to have an equal amount of information. Ducrocq and Quaas (1988) described the algorithm to calculate the relevant truncation point, given the number of animals to be selected and the number of candidates in each age class (table II).

Table II. Age distribution (years) of candidates for selection.

\begin{tabular}{lccccccccccccc}
\hline Breeding animals & 1 & 2 & 3 & 4 & 5 & 6 & 7 & 8 & 9 & 10 & 11 & 12 & 13 \\
\hline Cows & 0.16 & 0.15 & 0.13 & 0.11 & 0.09 & 0.08 & 0.07 & 0.06 & 0.05 & 0.04 & 0.03 & 0.02 & 0.01 \\
Bull dams & - & - & 0.19 & 0.16 & 0.13 & 0.11 & 0.10 & 0.09 & 0.07 & 0.06 & 0.04 & 0.03 & 0.01 \\
Farm NS bulls & 0.45 & 0.20 & 0.13 & 0.07 & 0.06 & 0.05 & 0.02 & 0.01 & 0.01 & - & - & - & - \\
Station NS bulls & - & 0.36 & 0.24 & 0.13 & 0.11 & 0.09 & 0.04 & 0.03 & 0.02 & 0.01 & - & - & - \\
AI bulls & - & - & - & - & 0.11 & 0.11 & 0.11 & 0.11 & 0.11 & 0.11 & 0.11 & 0.11 & 0.11 \\
\hline
\end{tabular}

$$
S_{X Y W}=\sum_{i} a_{X Y W}(i) s_{X Y W}(i) \quad \text { with } \quad a_{X Y W}(i)=\frac{f_{X Y}(i) p_{X Y W}(i)}{P_{X Y W}}
$$


where

$p_{X Y W}(i)$ is the proportion of animals selected in $W$ from cohort $X$ of age $i$ to produce the offspring $Y$

$f_{X Y}(i)$ is the fraction of candidates for selection to produce offspring $Y$, belonging to the cohort $X$ of age $i$ compared to all cohorts $\langle X, i\rangle$

$P_{X Y W}$ is the total proportion of animals selected in $W$ from cohorts $\langle X, i\rangle$ to produce the offspring $Y: P_{X Y W}=\sum_{i} f_{X Y}(i) p_{X Y W}(i)$. Generation intervals are easily derived as: $L_{X Y W}=\sum_{i} a_{X Y W}(i) i$.

The method described by Tallis (1961) is used to derive within-cohort selection differentials $s_{X Y W}(i)$ after a multistage selection, assuming a multivariate normal distribution of traits and treating candidates for selection as independent observations. As proposed by Ducrocq and Colleau (1986), numerical integration is carried out by Dutt's method. A 2-step selection is considered for bull dams and station NS bulls and a 3-step selection for AI bulls. Only cow dams and farm NS bulls are selected in one step.

Second step of the algorithm: derivation of asymptotic annual genetic gains and lags

An arbitrary reference cohort of mean genetic level $M_{1}$ is used to define $(n-1)$ independent genetic lags $C_{Y}$ as: $C_{Y}=M_{Y}-M_{1}$ for $Y=2$ to $n$.

$$
\mathbf{T}=\left(\begin{array}{ll}
t_{11} & \mathbf{T}_{12} \\
\mathbf{T}_{21} & \mathbf{T}_{22}
\end{array}\right)
$$

is the transition matrix between breeding values at birth of parents $X$ and progeny $Y$. Each element $t_{i j}$ represents the average fraction of genotype of progeny $i$ which is identical to genotype of parent $j$; thus, the $t_{i j}$ s are probabilities of gene transmission. $\mathbf{T}$ is partitioned into 4 sub-matrices: $t_{11}$ is a scalar, $\mathbf{T}_{12}$ is a row vector with elements $t_{1 k}, \mathbf{T}_{21}$ is a column vector with elements $t_{k 1}$ for $k=2 \ldots n$, and $\mathbf{T}_{22}$ is a matrix of $(n-1) \times(n-1)$ size.

$$
\mathbf{U}=\left(\begin{array}{c}
u_{1} \\
\mathbf{U}_{2}
\end{array}\right)
$$

is the vector of the average generation intervals after weighting by the above probabilities of gene transmission; $u_{1}$ is the average generation interval for progeny cohort $1, \mathbf{U}_{2}$ is the vector of the $(n-1)$ other progeny cohorts.

$$
\mathbf{V}=\left(\begin{array}{c}
v_{1} \\
\mathbf{V}_{2}
\end{array}\right)
$$

is the vector of the corresponding average selection differentials. 
The asymptotic result is then:

$$
\left(\begin{array}{c}
\Delta G \\
C_{2} \\
\vdots \\
C_{n}
\end{array}\right)=\left[\begin{array}{cc}
u_{1} & -\mathbf{T}_{12} \\
\mathbf{U}_{2} & \left(\mathbf{I}_{n-1}-\mathbf{T}_{22}\right)
\end{array}\right]^{-1}\left(\begin{array}{c}
v_{1} \\
\mathbf{V}_{2}
\end{array}\right)
$$

The first step of the demonstration is to derive mean genetic values $M_{Y}$ of all cohorts $Y$ at birth, by considering the average genetic values of parental cohorts $X$ :

$$
M_{Y}=\frac{1}{2}\left\{\sum_{X} b_{X Y} \sum_{W} \sum_{i} \omega_{X Y W}(i)\left[A_{X}(i)+s_{X Y W}(i)\right]\right\}
$$

where:

$A_{X}(i)$ is the mean genetic level at birth of parental cohort $X, i$ years before the birth of their offspring $Y$. As the mean genetic level of each cohort at birth is assumed to increase asymptotically with a constant rate per year $\Delta G, A_{X}(i)$ can be expressed as:

$$
A_{X}(i)=M_{X}-i \cdot \Delta G
$$

$\omega_{X Y W}(i)$ is the proportion of parents selected in $W$ from cohort of age $i$, among the parents $X$ of offspring $Y, b_{X Y}$ is the intra-sex proportion of parents of type $X$ used to produce offspring $Y$.

Thus,

$$
\sum_{X=1}^{m} b_{X Y}=\sum_{X=m+1}^{n} b_{X Y}=1
$$

where $m$ is the number of male cohorts and $n-m$ the number of female cohorts.

Provided that the asymptotic state is reached and pooling equations [1] and [2], the following equation is obtained:

$$
M_{Y}=\frac{1}{2}\left\{\sum_{X=1}^{m} b_{X Y} M_{X}+\sum_{X=m+1}^{n} b_{X Y} M_{X}-\left(\lambda_{1 Y}+\lambda_{2 Y}\right) \Delta G+\left(\delta_{1 Y}+\delta_{2 Y}\right)\right\}
$$

$X=1$ to $m$ corresponds to the different cohorts of sires; $X=m+1$ to $n$ corresponds to the cohorts of dams. $\lambda_{i Y}$ and $\delta_{i T}$ are the average generation interval and the average selection differential respectively of selected animals of sex $i$ to produce offspring $Y$.

By defining

$$
u_{Y}=\frac{\lambda_{1 Y}+\lambda_{2 Y}}{2} \quad \text { and } \quad V_{Y}=\frac{\delta_{1 Y}+\delta_{2 Y}}{2}
$$


the following system can be written in matrix notation:

$$
\left(\begin{array}{c}
M_{1} \\
M_{2} \\
\vdots \\
M_{n}
\end{array}\right)=\mathbf{T}\left(\begin{array}{c}
M_{1} \\
M_{2} \\
\vdots \\
M_{n}
\end{array}\right)-\mathbf{U} \Delta G+\mathbf{V}
$$

Equation [3] can be rewritten with the mean genetic level of all cohorts $Y$ (at any time) expressed in reference to the cohort $Y=1$ at time $t: C_{Y}=M_{Y}-M_{1}$.

Thus, at time $t$ :

$$
\left(\begin{array}{c}
0 \\
C_{2} \\
\vdots \\
C_{n}
\end{array}\right)=\left(\begin{array}{cc}
t_{11} & \mathbf{T}_{12} \\
\mathbf{T}_{21} & \mathbf{T}_{22}
\end{array}\right)\left(\begin{array}{c}
0 \\
C_{2} \\
\vdots \\
C_{n}
\end{array}\right)-\left(\begin{array}{c}
u_{1} \\
\mathbf{U}_{2}
\end{array}\right) \Delta G+\left(\begin{array}{c}
v_{1} \\
\mathbf{V}_{2}
\end{array}\right)
$$

At time $t+1$, the improvement rate is $\Delta G$ for each cohort and, thus, the first line of the previous system becomes:

$$
\begin{gathered}
\Delta G=\left[\begin{array}{ll}
t_{11} & \mathbf{T}_{12}
\end{array}\right]\left(\begin{array}{c}
\Delta G \\
C_{2}+\Delta G \\
\vdots \\
C_{n}+\Delta G
\end{array}\right)-u_{1} \Delta G+v_{1} \\
\Delta G=\mathbf{T}_{12}\left(\begin{array}{c}
C_{2} \\
\vdots \\
C_{n}
\end{array}\right)+\left(-u_{1}+\sum_{i=1}^{n} \eta_{i}\right) \Delta G+v_{1}
\end{gathered}
$$

where $\eta_{i}$ is the $i$ th term of the row vector $\left[\begin{array}{ll}t_{11} & \mathbf{T}_{12}\end{array}\right]$.

Because

$$
\sum_{i=1}^{n} \eta_{i}=\frac{1}{2}\left(\sum_{X=1}^{m} b_{X 1}+\sum_{X=m+1}^{n} b_{X 1}\right)=1
$$

pooling equation [5] with the $n-1$ last rows of equation [4] gives:

$$
\left(\begin{array}{c}
\Delta G \\
C_{2} \\
\vdots \\
C_{n}
\end{array}\right)=\left(\begin{array}{cc}
1-u_{1} & \mathbf{T}_{12} \\
-\mathbf{U}_{2} & \mathbf{T}_{22}
\end{array}\right)\left(\begin{array}{c}
\Delta G \\
C_{2} \\
\vdots \\
C_{n}
\end{array}\right)+\left(\begin{array}{c}
v_{1} \\
\mathbf{V}_{2}
\end{array}\right)
$$

Appendix II shows the equivalence of this results with the Rendel and Robertson (1950) formula in a closed homogeneous population. 


\section{Uncertainty in predicting genetic gain and lags}

The genetic parameters used in the present study for direct and maternal effects at 120 and $210 \mathrm{~d}$ were estimated by Shi et al (1993) in the Limousin breed. The other genetic parameters were taken from the review by Renand et al (1992). These parameters are presented in our previous paper (Phocas et al, 1995). Accuracies of selection indices to predict $\mathrm{Hg}$ are presented in table III. The procedure proposed by Foulley and Ollivier (1986) was used to test whether phenotypic and genetic covariance matrices were coherent.

Table III. Information sources and accuracy in predicting the global breeding objective $\mathrm{Hg}$.

\begin{tabular}{lc}
\hline Description $^{\text {a }}$ & Accuracy to predict $H g$ \\
\hline Bull selection & \\
Individual W210 & 0.45 \\
Individual W400 & 0.45 \\
Progeny index $I_{\mathrm{b}}$ & 0.75 \\
Cow selection indices & \\
0 calf recorded: $I_{0}$ & 0.32 \\
1 calf recorded: $I_{1}$ & 0.40 \\
5 calves recorded: $I_{5}$ & 0.50 \\
10 calves recorded: $I_{10}$ & 0.53 \\
\hline
\end{tabular}

${ }^{\text {a }}$ See Appendix I for an overall description of the selection indices.

As stressed by Meyer (1992), sampling covariances of estimates of variance components including maternal effects are very high, even for designs specifically dedicated to the estimation of maternal effects. However, in most cases, sampling covariances of such estimates are not calculated because of high computing costs. Thus, a theoretical structure of data was constructed to evaluate sampling variances and covariances between preweaning genetic parameters (Phocas et al, 1995). The sampling variance-covariance matrix is derived for 4050 observations originated from 90 unrelated sires and 90 unrelated maternal grandsires with 45 bulls used as sires of 90 calves and as maternal grandsires of 90 other calves. The calculated uncertainty in direct variances corresponds to values frequently found in the literature (coefficient of variation around $20 \%$ ).

In order to take into account such an uncertainty in preweaning genetic parameters (vector $\widehat{\boldsymbol{\theta}}$ ), variances of asymptotic predicted genetic gain and genetic lags are derived using the first-order term of a Taylor expansion with derivatives calculated by finite differences:

$$
\operatorname{Var}\left(\begin{array}{c}
\Delta G \\
C_{2} \\
\vdots \\
C_{n}
\end{array}\right) \approx \mathbf{G}(\widehat{\boldsymbol{\theta}})^{\prime} \operatorname{Var}(\widehat{\boldsymbol{\theta}}) \mathbf{G}(\widehat{\boldsymbol{\theta}}) \text { where } \mathbf{G}(\widehat{\boldsymbol{\theta}})=\left[\frac{\partial}{\partial \boldsymbol{\theta}}\left(\begin{array}{c}
\Delta G \\
C_{2} \\
\vdots \\
C_{n}
\end{array}\right)\right]_{\boldsymbol{\theta}=\hat{\boldsymbol{\theta}}}
$$




\section{RESULTS AND DISCUSSION}

\section{Asymptotic genetic gains}

In this study, we have focused on asymptotic genetic gain (table IV) in order to discriminate among different breeding plans since this criterion is not influenced by the initial state of the population. Therefore, we ignore commercial herds since there are no genes returned to the nucleus and thus, asymptotically the overall population progresses genetically at the same rate as the nucleus (Bichard, 1971; Elsen, 1980).

Table IV. Annual asymptotic genetic gains (in $\%$ of genetic standard deviation) and corresponding sampling coefficients of variation (in \%, between brackets).

\begin{tabular}{|c|c|c|c|c|}
\hline Breeding scheme & $\mathrm{Hg}$ & A210 & M210 & $A 500$ \\
\hline \multicolumn{5}{|l|}{ One-tier nucleus ${ }^{\mathrm{a}}$} \\
\hline Full selection & $\begin{array}{c}13.5(10) \\
\text { or } 22.6 \mathrm{FF}\end{array}$ & $\begin{array}{c}11.9(13) \\
\text { or } 1.38 \mathrm{~kg}\end{array}$ & $\begin{array}{c}4.9(47) \\
\text { or } 0.42 \mathrm{~kg}\end{array}$ & $\begin{array}{l}10.2(12) \\
\text { or } 2.97 \mathrm{~kg}\end{array}$ \\
\hline \multicolumn{5}{|l|}{ Two-tier nucleus ${ }^{\mathrm{b}}$} \\
\hline Full selection & $\begin{array}{c}14.6(9) \\
\text { or } 24.5 \mathrm{FF}\end{array}$ & $\begin{array}{c}12.9(12) \\
\text { or } 1.50 \mathrm{~kg}\end{array}$ & $\begin{array}{c}5.2(48) \\
\text { or } 0.44 \mathrm{~kg}\end{array}$ & $\begin{array}{l}11.2(12) \\
\text { or } 3.26 \mathrm{~kg}\end{array}$ \\
\hline No dam selection & $\begin{array}{c}10.7 \\
\text { or } 17.9 \mathrm{FF}\end{array}$ & $\begin{array}{l}10.6 \\
\text { or } 1.23 \mathrm{~kg}\end{array}$ & $\begin{array}{c}1.3 \\
\text { or } 0.11 \mathrm{~kg}\end{array}$ & $\begin{array}{c}9.1 \\
\text { or } 2.65 \mathrm{~kg}\end{array}$ \\
\hline No farm NS bull selection & $\begin{array}{c}12.2 \\
\text { or } 20.4 \mathrm{FF}\end{array}$ & $\begin{array}{l}10.6 \\
\text { or } 1.23 \mathrm{~kg}\end{array}$ & $\begin{array}{c}4.3 \\
\text { or } 0.37 \mathrm{~kg}\end{array}$ & $\begin{array}{c}9.5 \\
\text { or } 2.76 \mathrm{~kg}\end{array}$ \\
\hline Only station NS and AI bull selection & $\begin{array}{c}6.6 \\
\text { or } 11.0 \mathrm{FF}\end{array}$ & $\begin{array}{c}6.4 \\
\text { or } 0.74 \mathrm{~kg}\end{array}$ & $\begin{array}{c}0.8 \\
\text { or } 0.07 \mathrm{~kg}\end{array}$ & $\begin{array}{c}5.8 \\
\text { or } 1.69 \mathrm{~kg}\end{array}$ \\
\hline
\end{tabular}

${ }^{\mathrm{a}}$ One-tier nucleus: $11.5 \%$ of calves born bred by $\mathrm{AI}$ in all herds; ${ }^{\mathrm{b}}$ two-tier nucleus: $23 \%$ of calves born bred by $\mathrm{AI}$ in $50 \%$ of herds.

\section{Expected values}

Concentrating $\mathrm{AI}$ in half of the selection nucleus leads to higher expected genetic gains ( $+8 \%$ in $\mathrm{Hg}$ and $\mathrm{A} 210,+10 \%$ in A500 and $+6 \%$ in M210) than using $\mathrm{AI}$ all over the selection nucleus. The tier defined by herds using AI must be considered as the elite subnucleus; the major part of genetic improvement is created in that tier.

The expected asymptotic genetic gain in final weight lies above the value $(8 \%$ of a genetic standard deviation) calculated by Colleau and Elsen (1988). These authors assumed no dam-to-daughter selection and excluded from the selection nucleus animals bred by NS. Expected asymptotic genetic gain in direct effects on weaning weight is 4 times as large as the observed gain, estimated by the best linear unbiased prediction (BLUP) animal model method over the period from 1972 to 1994 (unpublished results). The expected asymptotic gain in M210 is small but real, 
whereas the observed gain is estimated to be nil. The importance of the difference between observed and expected genetic gains is probably mainly related to losses of efficiency in the implementation of the modelled breeding scheme. Other causes can also explain a part of the difference; the steady-state equilibrium is probably not reached since the current breeding scheme has been only implemented since 1980. Reduction of genetic variance due to selection, inbreeding and increased relationships between animals are not considered in our study.

In order to evaluate the importance of the selection of each kind of breeding animals, some selection paths were suppressed to derive genetic gains in the 2-tier nucleus. The main part of genetic improvement is due to the selection of AI and station NS bulls; it accounts for $45 \%$ of the genetic improvement in $\mathrm{Hg}$ and for $15 \%$ in M210, whereas these bulls are sires of only $23 \%$ of the calves born. Farm NS bulls are sires of $77 \%$ of the calves born, but account for only $15 \%$ of the genetic gains in $\mathrm{Hg}$ and M210. Dam selection accounts for about 30\% of the genetic gains in $\mathrm{Hg}$ and M210. Dam selection accounts for about 30\% of the genetic gains in $\mathrm{Hg}$ and $75 \%$ in M210. Consequently, genetic improvement in maternal effects is mainly due to cow selection on farm.

\section{Uncertainty due to the estimation of preweaning parameters}

The uncertainty in genetic gains is independent of the structure of the nucleus (table IV). The coefficients of variation of direct and global responses are around $10 \%$; the coefficient of variation of maternal response is nearly $50 \%$. Predicted genetic responses seem to be robust to values of genetic parameters since coefficients of variation for predicted genetic responses are smaller than those of estimated genetic parameters, at least as far as direct and global responses are considered. The uncertainty in maternal genetic response is intermediate between uncertainty in maternal (co)variances (33\%) and uncertainty in direct-maternal covariances $(100 \%)$. Such a result is in contrast to the results of Sales and Hill $(1976 \mathrm{a}, \mathrm{b})$ on the variance of predicted responses due to index selection. However here we consider a complex breeding scheme with multistage selection and use of different indices according to the stage of selection and the kind of breeding animal considered.

Sampling correlations between responses are highly positive: 0.9 between global and direct genetic gain; 0.8 between global and maternal responses; 0.99 between direct responses for A210 and A500; 0.7 between responses for A500 and M210; and 0.6 between responses for A210 and M210. Hence, overestimation (or underestimation) on direct responses is correlated to overestimation (or underestimation) on maternal genetic gain. This is related to small (0.07) but positive sampling correlations between direct and maternal variances. Moreover, selection is mainly performed on optimum indices combining direct and maternal performance. Both direct and maternal responses should be as large as possible to maximize the response on the breeding objective.

Positive responses in M210 may be considered as significant if genetic gains are assumed to be normally distributed. Estimated values of genetic correlations between direct and maternal effects are in the average range of values seen in the literature (around -0.2 ; Shi, 1993). Nevertheless, much more negative values are sometimes estimated or suspected in extensive production systems. If values 
of genetic correlations between direct and maternal effects were assumed equal to -0.6 , a negative response occurred in $\mathrm{M} 210\left(-2.5 \% \sigma_{M 210}\right)$ and losses of efficiency were 10 and $18 \%$ in direct effects and in the breeding objective respectively. Thus, responses are very dependent on the values of direct-maternal covariances, when these are the worst estimated parameters.

\section{Genetic lags}

Genetic lags (table V) between sexes are shorter than 6 months since selection of bulls was assumed to be independent of the sex of progeny. Uncertainty in these lags is important. Genetic lags between origins are larger, but with a smaller relative uncertainty. Concentrating AI use (2-tier nucleus) increases genetic lags between populations bred by AI and NS. Between tiers, the genetic lag for males bred by NS is around 2 years. Within the elite tier, the genetic lag between calves bred by $\mathrm{AI}$ and NS is around 6 years. This underlines the necessity of classifying animals into cohorts according to the reproduction method in order to derive proper genetic gains.

Table V. Examples of genetic lags in $H \mathrm{~g}$ (in $\%$ of $\sigma_{\mathrm{H}}$ ) and corresponding sampling coefficients of variation (in \%, between brackets).

\begin{tabular}{lcc}
\hline Genetic lag $^{\mathrm{a}}$ & One-tier nucleus & Two-tier nucleus \\
\hline M1-F1 & $2(33)$ & $7(14)$ \\
M3-F3 & - & $5(26)$ \\
M1-M2 & $82(6)$ & $88(6)$ \\
M2-M3 & - & $31(10)$ \\
\hline
\end{tabular}

a M1-F1: lag between males and females bred by AI; M3-F3: lag between males and females bred by NS in herds without AI use; M1-M2: lag between males bred by AI and NS in herds with AI use; M2-M3: lag between males bred by NS in herds with and without AI use.

\section{Origin of parents of each cohort of calves}

The optimal proportions (according to origin) of the parents for each cohort of calves are derived in order to maximize genetic gain in the breeding objective (table VI). Males are selected to produce offspring in both tiers, independently of their origin (reproduction method and native tier); females are selected to produce offspring in their native tier, but independently of their reproduction method. Uncertainties in these optimal proportions are quite small.

\section{Origin of dams}

The optimum proportion of cow dams bred by AI is $18 \%$ in the one-tier nucleus and $35 \%$ in the elite tier of the 2 -tier nucleus. The proportion of bull dams bred by AI is bigger, $20 \%$ in the one-tier nucleus and $42 \%$ in the elite tier of the 2-tier nucleus, 
Table VI. Proportions of parents per origin (in \%) and corresponding coefficients of variation (in \%, between brackets).

\begin{tabular}{|c|c|c|}
\hline Parental origin ${ }^{\mathrm{a}}$ & One-tier nucleus & Two-tier nucleus \\
\hline \multicolumn{3}{|l|}{ Cow dam born } \\
\hline \multicolumn{3}{|c|}{ In herds with AI use } \\
\hline $\mathrm{F} 1$ & $15(5)$ & $35(6)$ \\
\hline $\mathrm{F} 2$ & $82(3)$ & $65(3)$ \\
\hline \multicolumn{3}{|c|}{ In herds without AI use } \\
\hline F3 & - & 100 \\
\hline \multicolumn{3}{|c|}{ Bull dams born } \\
\hline \multicolumn{3}{|c|}{ In herds with AI use } \\
\hline $\mathrm{F} 1$ & $20(7)$ & $42(8)$ \\
\hline $\mathrm{F} 2$ & $80(4)$ & $58(6)$ \\
\hline \multicolumn{3}{|c|}{ In herds without AI use } \\
\hline F3 & - & 100 \\
\hline \multicolumn{3}{|l|}{ AI sires born } \\
\hline M1 & $91(1)$ & $97(2)$ \\
\hline M2 & $9(30)$ & $3(50)$ \\
\hline M3 & - & $0(53)$ \\
\hline \multicolumn{3}{|c|}{ Station NS sires born } \\
\hline M1 & $26(1)$ & $32(32)$ \\
\hline M2 & $74(1)$ & $37(1)$ \\
\hline M3 & - & $31(3)$ \\
\hline \multicolumn{3}{|c|}{ Farm NS sires born } \\
\hline M1 & $19(3)$ & $21(2)$ \\
\hline M2 & $81(2)$ & $38(3)$ \\
\hline M3 & - & $41(4)$ \\
\hline
\end{tabular}

a See Appendix I for the meaning of abbreviations used.

due to a more intense selection. Whatever the structure of the nucleus, around $20 \%$ of all dams are bred by AI in the asymptotic optimal situation, whereas, in reality, only $10 \%$ of the dams are bred by AI.

\section{Origin of AI sires}

In a one-tier nucleus, $91 \%$ of AI bulls are themselves bred by AI. In a 2-tier nucleus, this proportion is even larger $(97 \%)$ due to a small increase of the lag between males bred by AI and males bred by NS. The other AI bulls are bred by NS in herds with AI use. Thus $100 \%$ of AI bulls are born in the elite tier, ie in herds with AI use. This optimal strategy is far from reality; currently around $40 \%$ of AI bulls are bred by AI.

\section{Origin of NS sires}

Whatever the structure of the nucleus, there is a greater proportion of sires bred by AI among station NS bulls (13.3\% of NS bulls) than among farm NS bulls. In the 
2-tier nucleus, $63.5 \%$ of NS bulls are born in the elite tier. The optimal proportions of NS bulls bred by AI are 20 and $23 \%$ in a one-tier and 2-tier nuclei respectively, whereas the current proportion is around $10 \%$.

\section{Generation intervals and selection differentials}

Whatever the structure of the nucleus, optimal generation intervals are similar (table VII). Optimal values of generation intervals are also quite independent of the uncertainty in genetic parameters; the coefficients of variation are smaller than $2 \%$.

Table VII. Average generation intervals ${ }^{\mathrm{a}}$ and selection differentials in $\mathrm{Hg}$ (in $\%$ of $\sigma_{\mathrm{H}}$ ) with range of coefficients of variation (in \%, between brackets).

\begin{tabular}{lccccc}
\hline Selection path & \multicolumn{2}{c}{ One-tier nucleus } & & \multicolumn{2}{c}{ Two-tier nucleus } \\
\cline { 2 - 3 } \cline { 5 - 6 } & $\begin{array}{c}\text { Generation } \\
\text { interval (year) }\end{array}$ & $\begin{array}{c}\text { Selection } \\
\text { differential }\end{array}$ & $\begin{array}{c}\text { Generation } \\
\text { interval (year) }\end{array}$ & $\begin{array}{c}\text { Selection } \\
\text { differential }\end{array}$ \\
\hline Cow dam & 6.2 & $39(30-50)$ & 6.2 & $26(30-50)$ \\
Bull dam & 7.2 & $56(20-40)$ & & 7.0 & $49(20-40)$ \\
AI sire & 7.6 & $312(10)$ & & 7.6 & $316(10)$ \\
Farm + station NS sire & 4.0 & $98(10-20)$ & & 4.0 & $88(10-20)$
\end{tabular}

a Average according to the origin of parents; the range given between brackets on coefficients of variation corresponds to the selection differentials per origin.

Except for the average AI sires path, taking into account 2 tiers leads to smaller average selection differentials; $-30 \%$ on the cow dams path and $-10 \%$ on the bull dams and NS sires paths. Since animals born in the elite tier (herds with AI use) have a higher average genetic level than animals born in the second tier, a greater proportion of males is selected in the elite tier and thus, selection differential is reduced. The AI sires' average selection differential is nearly unchanged since the large proportion of AI bulls is selected from males bred by AI, whose number is the same in both cases. These results are in apparent contradiction with the fact that genetic gains are bigger in the 2-tier nucleus than in the one-tier one. Using the Rendel and Robertson (1950) formula, annual genetic gain in $\mathrm{Hg}$ would have been overestimated whatever the structure of the nucleus. Moreover, a smaller value would have been derived in the 2 -tier nucleus ( $15.6 \%$ of genetic standard deviation) than in the one-tier one $(16.9 \%$ of genetic standard deviation). However genetic gain cannot be calculated as a simple sum on each selection path, weighted by the proportion of calves born from the associated kind of parents. It depends on the gene flow between and within tiers and between the animals bred by AI and by NS.

Concerning the uncertainty, the coefficients of variation of selection differentials are similar whatever the nucleus structure. They are much larger on dam-selection paths than on sire-selection paths. This must be related to the fact that dam selection is more dependent on direct-maternal covariances, which are the less accurate estimates. Uncertainty in genetic gain in $\mathrm{Hg}$ is in the range of uncertainty about AI sires' selection differential. This underlines the importance of an accurate selection of AI sires. 


\section{CONCLUSION}

French beef cattle breeding schemes, such as that currently in place for the Limousin breed, can provide significant annual genetic gain for objectives concerning direct and maternal effects on growth, even if genetic parameters are not very well known. However a full evaluation of the efficiency of such selection schemes depends on the inclusion in the model of other beef traits (eg, feed efficiency and carcass quality) and maternal performance ( $e g$, fertility and ease of calving). Beef cattle breeding schemes can be efficient despite a small number of inseminations concentrated in only a part of a herd. Our study ignores the problem of correcting performance for systematic environmental effects. Their estimation requires genetic connections between herds, which would be more difficult to set up when AI is not used in all herds. When this difficulty is overcome, our study shows that it can be advantageous, at a constant overall rate of $\mathrm{AI}$ in the selection nucleus, to concentrate $\mathrm{AI}$ in a part of herds. Consequently, when it is unrealistic to increase AI rate in all herds, one way to improve the efficiency of the breeding scheme may be to maintain a basic rate of $\mathrm{AI}$ in all herds to ensure genetic connections and then to increase AI rate in only a part of the herds.

\section{REFERENCES}

Bichard M (1971) Dissemination of genetic improvement through a livestock industry. Anim Prod 13, 401-411

Colleau JJ, Elsen JM (1988) Potentialities of embryo transfer to improvement of beef cattle and sheep productivity. $3^{e}$ Congrès Mondial de Reproduction et Sélection des Ovins et Bovins à Viande. Paris, 19-26 juin 1988. INRA, France, vol 1, 141-157

Ducrocq V, Colleau JJ (1986) Interest in quantitative genetics of Dutt's and Deak's methods for numerical computation of multivariate normal probability integrals. Genet Sel Evol 18, 447-474

Ducrocq V, Quaas RL (1988) Prediction of genetic response to truncation across generations. J Dairy Sci 71, 2543-2553

Elsen JM (1980) Diffusion du progrès génétique dans les populations avec générations imbriquées : quelques propriétés d'un modèle de prévision. Ann Génét Sél Anim 12, $49-80$

Elsen JM (1993) Prediction of annual genetic gain and improvement lag between populations. Genet Sel Evol 25, 75-82

Foulley JL, Ollivier L (1986) A note on criteria of coherence for the parameters used to construct a selection index. J Anim Breed Genet 103, 81-86

James JW (1977) Open nucleus breeding systems. Anim Prod 24, 287-305

Meyer K (1992) Bias and sampling covariances of estimates of variance components due to maternal effects. Genet Sel Evol 24, 487-509

Phocas F, Colleau JJ, Ménissier F (1995) Expected efficiency of selection for growth in a French beef cattle breeding scheme : I. Multistage selection of bulls used in artificial insemination. Genet Sel Evol 27, 149-170

Renand G, Plasse D, Andersen BB (1992) Genetic improvement of cattle growth and carcass traits. In: Beef Cattle Production. (R Jarrige, C Beranger, ed), Elsevier, The Netherlands, 86-107

Rendel JM, Robertson A (1950) Estimation of genetic gain in milk yield by selection in a close herd of dairy cattle. $J$ Genet 50, 1-8 
Sales J, Hill WG (1976a) Effect of sampling errors on efficiency of selection indices. I. Use of information from relatives for single trait improvement. Anim Prod 22, 1-17

Sales J, Hill WG (1976b) Effect of sampling errors on efficiency of selection indices. II. Use of information on associated traits for improvement of a single important trait. Anim Prod 23, 1-14

Shepherd RK, Kinghorn BP (1992) Optimising multi-tier open nucleus breeding schemes. Theor Appl Genet 85, 372-378

Shi MJ, Laloë D, Ménissier F, Renand G (1993) Estimation of genetic parameters of preweaning performance in the French Limousin cattle breed. Genet Sel Evol 25, $177-189$

Tallis GM (1961) The moment generating function of the truncated multi-normal distribution. J R Stat Soc 323, 223-229

\section{APPENDIX I. Meaning of the abbreviations used}

\section{Selection indices}

W120: weight at $120 \mathrm{~d}$

W210: weight at $210 \mathrm{~d}$ or weaning weight

W400: weight at $400 \mathrm{~d}$

W500: weight at $500 \mathrm{~d}$ or final weight

$I_{\mathrm{b}}$ : index on bulls' progeny combining the average W210 of 30 sons with the average W120 of 20 daughters' calves

$I_{0}$ : index combining the own W120 of a heifer with the average W120 of the first calf of 10 paternal half-sisters

$I_{1}, I_{5}, I_{10}, I_{\mathrm{d}}$ : index combining the own $\mathrm{W} 120$ of a dam with the average W120 of the first calf of 10 paternal half-sisters and with the W120 of respectively $1,5,10$ and d calves of the dam

\section{Breeding values}

A120: direct effects on W120

M120: maternal effects on W120

A210: direct effects on W210

M210: maternal effects on W210

A400: direct effects on $\mathrm{W} 400$

A500: direct effects on W500

\section{Cohorts at birth}

M1 (F1): males (females) bred by A1

M2 (F2): males (females) bred by NS in herds with AI use

M3 (F3): males (females) bred by NS in herds without AI use 
APPENDIX II. Deriving Rendel and Robertson formula (1950) from our general matrix equation

In a one-tier homogeneous nucleus, only 2 birth cohorts must be considered: males $(Y=1)$ and females $(Y=2)$.

$$
\begin{aligned}
& \mathbf{T}=\left(\begin{array}{cc}
\frac{1}{2} & \frac{1}{2} \\
\frac{1}{2} & \frac{1}{2}
\end{array}\right), \mathbf{U}=\left(\begin{array}{c}
u_{1} \\
u_{2}
\end{array}\right)=\left(\begin{array}{c}
\frac{L_{11}+L_{21}}{2} \\
\frac{L_{12}+L_{22}}{2}
\end{array}\right) \text { and } \mathbf{V}=\left(\begin{array}{l}
v_{1} \\
v_{2}
\end{array}\right)=\left(\begin{array}{c}
\frac{S_{11}+S_{21}}{2} \\
\frac{S_{12}+S_{22}}{2}
\end{array}\right) \\
&\left(\begin{array}{c}
\Delta G \\
C_{2}
\end{array}\right)=\left[\begin{array}{cc}
u_{1} & -0.5 \\
u_{2} & 0.5
\end{array}\right]^{-1}\left(\begin{array}{c}
v_{1} \\
v_{2}
\end{array}\right)=\frac{1}{0.5 u_{1}+0.5 u_{2}}\left[\begin{array}{cc}
0.5 & 0.5 \\
-u_{2} & u_{1}
\end{array}\right]\left(\begin{array}{c}
v_{1} \\
v_{2}
\end{array}\right) \\
&=\left(\begin{array}{c}
\frac{v_{1}+v_{2}}{u_{1}+u_{2}} \\
\frac{-u_{2} \cdot v_{1}+u_{1} \cdot v_{2}}{0.5\left(u_{1}+u_{2}\right)}
\end{array}\right)
\end{aligned}
$$

Thus, $\Delta G=\frac{v_{1}+v_{2}}{u_{1}+u_{2}}=\frac{S_{11}+S_{21}+S_{12}+S_{22}}{L_{11}+L_{21}+L_{12}+L_{22}}$ 